\title{
Algunas consideraciones sobre la gestión del patrimonio paleontológico
}

\author{
Esperanza Fernández Martínez, Esperanza García-Ortiz de Landaluce | Universidad de León \\ URL de la contribución <www.iaph.es/revistaph/index.php/revistaph/article/view/4154>
}

El objetivo fundamenal del patrimonio debe ser la conservación, entendiendo por tal la preservación del valor del lugar u objetos considerados como tales, y su utilización con fines culturales (bien sean de investigación, enseñanza a diferentes públicos o turismo). Para lograr estos fines es fundamental realizar una labor de gestión que ha de tener en cuenta dos aspectos básicos:

$>$ el uso potencial al que se va a dedicar el lugar u objeto/s con valor patrimonial;

$>$ los rasgos específicos de cada patrimonio. Estos últimos dependen de los elementos físicos que los constituyen, $y$, en gran medida, determinan su riesgo de degradación.

\section{Algunos rasgos del patrimonio paleontológico \\ Por tratarse de objetos naturales pertenecientes a la geosfera, los fósiles y los yacimientos donde se encuen- tran comparten una serie de rasgos con otros tipos de patrimonio geológico. Entre ellos, cabe citar:}

1. Ser constituyentes habituales de las rocas sedimentarias.

\section{No ser renovables.}

3. Requerir exposición. Esta puede producirse por causas naturales (los yacimientos de icnitas de dinosaurio de la costa asturiana, por ejemplo) o por causas antrópicas (los yacimientos de Atapuerca o de Lo Hueco).

4. Tener alta capacidad explicativa. Los fósiles y sus yacimientos son documentos naturales que, convenientemente interpretados, nos muestran aspectos muy diversos sobre mundos hoy desaparecidos.
A mayores, el patrimonio paleontológico tiene rasgos que le son peculiares, aunque algunos de ellos están compartidos por otros tipos de patrimonio.

5. Duplicidad legal, al estar regido por normativas referidas tanto al patrimonio cultural como al natural, ninguna de las cuales ha logrado evitar ni la degradación de muchos yacimientos ni la pérdida de numerosas colecciones.

6. Estar formado por elementos muebles (los fósiles) e inmuebles (los yacimientos).

7. Ejercer una fuerte atracción para el público general, motivo por el cual son elementos de alto interés en actividades docentes, divulgativas y turístico-recreativas.

Muchos de estos rasgos, pero especialmente los números 1, 2, 4, 5 y 7, se conjugan para hacer del paleontológico un patrimonio con un altísimo riesgo de degradación, hecho de especial relevancia a la hora de gestionar cualquier patrimonio.

\section{Riesgo de degradación del patrimonio paleontológico} La figura que incluimos muestra los principales factores de riesgo de degradación de un yacimiento.

El riesgo por fragilidad lo poseen aquellos yacimientos que, por tener litologías fácilmente erosionables o formas de fosilización débiles, experimentan procesos intrínsecos de destrucción que no pueden frenarse con facilidad (por ejemplo, fósiles conservados en margas y sin partes mineralizadas). Algo similar ocurre con el riesgo por vulnerabilidad natural, aunque en este caso el proceso que destruye el yacimiento es externo y no está 


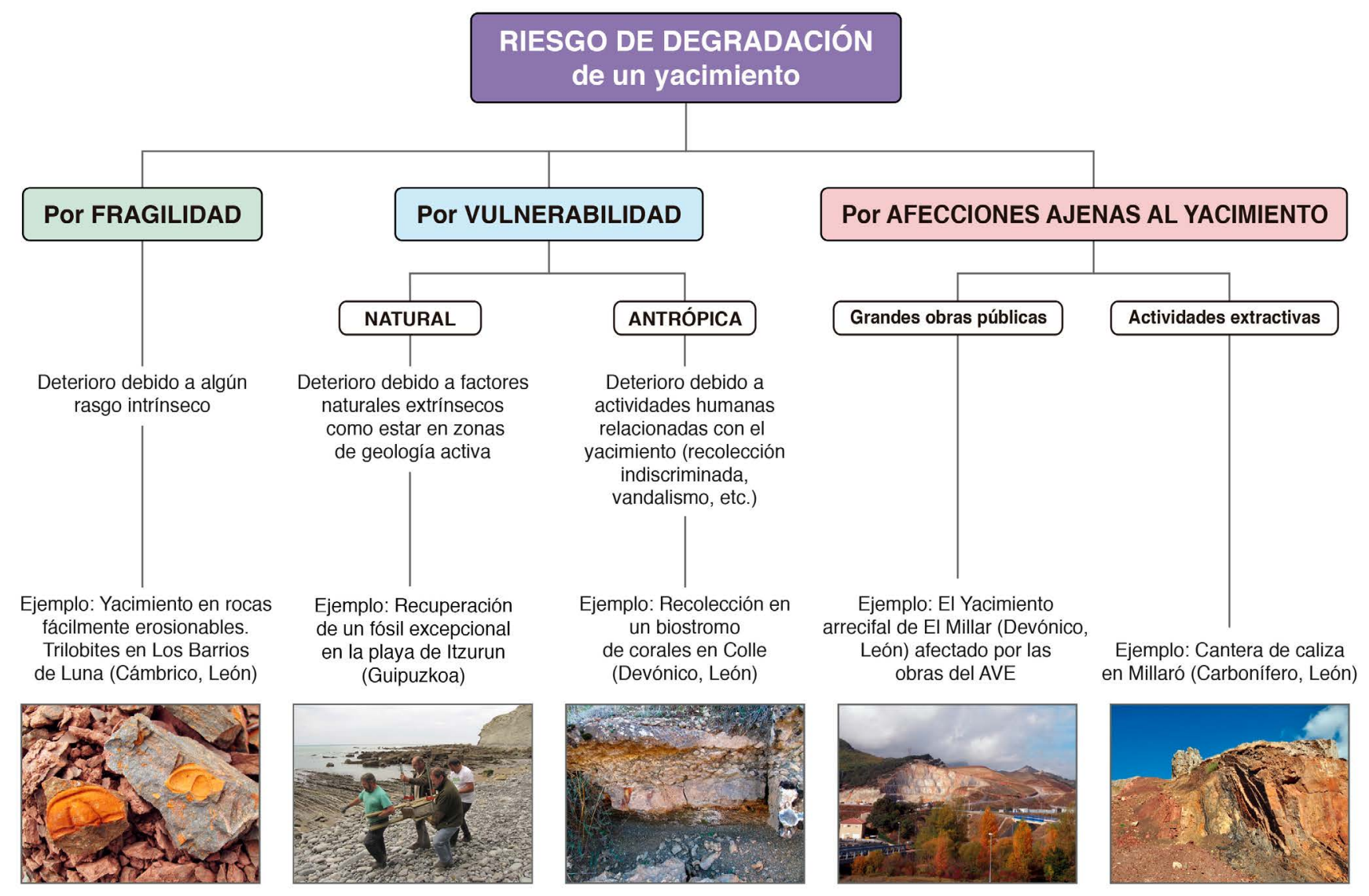

Esquema de los riesgos de degradación que amenazan el patrimonio paleontológico con un ejemplo de cada uno de ellos | esquema Esperanza Fernández Martínez a partir de datos en GARCÍA-ORTIZ; FUERTES-GUTIÉRREZ; FERNÁNDEZ-MARTÍNEZ, 2014; FUERTES-GUTIÉRREZ; GARCÍA-ORTIZ; FERNÁNDEZMARTÍNEZ, 2016 (fotografías de la autora excepto la imagen 2, cedida por Asier Hilario -Geoparque de la Costa Vasca-)

relacionado con el mismo (yacimientos en la costa cantábrica, por ejemplo).

El riesgo por vulnerabilidad antrópica en los yacimientos paleontológicos es, casi siempre, altísimo, ya que fósiles y yacimientos ejercen un gran atractivo sobre muchas personas. Este hecho, unido a los comportamientos vandálicos habituales que afectan a todo patrimonio, y al hecho de que "coger fósiles" ha sido una práctica muy extendida y aplaudida en el pasado, son los responsables de esta valoración.

Por último, el rasgo 1 (ser parte de las rocas sedimentarias) hace que el riesgo por afecciones ajenas al yaci- miento sea también alto, pero este caso es matizable. En primer lugar porque existen Estudios de Impacto Ambiental (EIA) que, bien desarrollados, pueden frenar la destrucción del yacimiento e incluso ayudar a su estudio. En segundo lugar porque, como se indicó en el rasgo 3, la actividad antrópica puede sacar a la luz un yacimiento.

\section{La gestión del patrimonio paleontológico}

Retomando la idea inicial, la gestión del patrimonio paleontológico tiene que estar orientada a dos objetivos básicos: 1/ preservar el valor del elemento y $2 /$ favorecer que este sea utilizado con fines culturales diversos. 
La preservación del valor del yacimiento o de sus fósiles debe realizarse utilizando diversas estrategias que están relacionadas con el riesgo de degradación y con el uso que se quiera dar al lugar o colección.

Así, la preservación de yacimientos cuyo riesgo principal se produce por fragilidad o por vulnerabilidad natural es casi imposible y, en muchos casos, se impone un estudio integral del mismo, la extracción de los fósiles y la creación de colecciones con fines científicos y/ o expositivos.

Los yacimientos que experimentan afecciones por grandes obras o por actividades extractivas deben tener una gestión especial, consistente en realizar EAI y, si es posible, en llegar a acuerdos con las empresas causantes de la afección para poder realizar los estudios pertinentes y obtener materiales de colección. En España tenemos magníficos ejemplos de este tipo de gestión (Túnel Ordovícico del Fabar, yacimiento de Lo Hueco, acuerdos de la Fundación Dinópolis con empresas que explotan recursos naturales en lugares con fósiles de vertebrados, etc.).

En los casos anteriores, el uso potencial de estos elementos patrimoniales (sean yacimientos y/o colecciones) está en la investigación científica, pudiendo desarrollarse posteriormente una fase divulgativa centrada en las colecciones obtenidas.

Por último, tenemos el caso de los yacimientos afectados por acciones antrópicas. Estas aluden al vandalismo y al expolio realizado por coleccionistas, comerciantes o público no especializado. Sin embargo, actividades docentes y prácticas científicas poco cuidadosas pueden también alterar el valor de un yacimiento. En estos casos, e independientemente del número o tipo de fósiles librados, resulta imprescindible regular la recolección en función de varios parámetros como el tipo de yacimiento y fósiles, su valor, estado de conservación y, sobre todo, del diferente uso que se le quiera dar (científico, docente, divulgativo, empresas turísticas, etc.) Ejemplos de buenas prácticas en la gestión de fósiles existen en varios países, como Gran Bretaña, donde se han desarrollado códigos que regulan la recolección y grupos de custodia locales que se ocupan de controlar las visitas.

Una regulación de este tipo sólo puede ser efectiva si existe un apoyo legislativo que incluya normativa sancionadora, si la guardería medioambiental se involucra en ella y, muy especialmente, si comenzamos una auto-educación centrada en la no recolección indiscriminada de ejemplares. Muchos fósiles y yacimientos se han perdido en los últimos años, así que no deberíamos esperar mucho más.

\section{BIBLIOGRAFÍA}

- GARCÍA-ORTIZ, E.; FUERTES-GUTIÉRREZ, I.; FERNÁN DEZ-MARTÍNEZ, E. (2014) Concepts and terminology for the risk of degradation of geological heritage sites: fragility and natural vulnerability, a case study. Proceedings of the Geologists' Association, vol. 125, 2014, pp. 463-479

- FUERTES-GUTIÉRREZ, I.; GARCÍA-ORTIZ, E.; FERNÁN DEZ-MARTÍNEZ, E. (2016) Anthropic Threats to Geological Heritage: Characterization and Management: A Case Study in the Dinosaur Tracksites of La Rioja (Spain). Geoheritage, vol. 8, n. ${ }^{\circ} 2$, 2016, 135-153. <https://doi.org/10.1007/s12371-015$0142-3>$ 